\title{
KEDUDUKAN DUDA MULIH TRUNA PADA PERKAWINAN NYENTANA DI BANJAR PUJUNG KAJA DESA SEBATU
}

\author{
Ni Luh Made Noviantini, I Ketut Sukadana, Diah Gayatri Sudibya \\ Fakultas Hukum Universitas Warmadewa, Denpasar - Bali, Indonesia
}

\begin{abstract}
Abstrak
Masyarakat Bali menganut sistem kekeluargaan pratilinial. Di Bali, kedudukan seorang laki-laki (purusa) sangatlah penting. Ada beberapa jenis perkawinan di Bali, salah satunya yaitu perkawinan nyentana. Seorang laki-laki yang melaksanakan perkawinan nyentana adalah dimana pihak laki-laki dipinang oleh pihak perempuan dan upacara perkawinannya dilaksanakan di rumah perempuan. Pada perkawinan nyentana ada banyak hal yeng mempengaruhi terjadinya perceraian, salah satunya adalah masalah warisan. Laki-laki yang sudah pernah nyentana kemudian kembali pulang keumah asalnya tidak berhak lagi untuk mewaris di rumah asalnya karena semua hak mewarisnya sudah hilang sejak ia sah melaksanakan perkawinan nyentana. Berdasarkan latar belakang tersebut di atas, penelitian ini dilakukan dengan tujuan menguraikan bagaimana status hukum duda mulih truna di rumah asalnya dan bagaimana hak mewaris duda mulih truna menurut awigawig di Banjar Pujung Kaja Desa Sebatu. Metode yang digunakan dalam penelitian hukum ini adalah metode penelitian hukum empiris. Hasil penelitian ini menunjukkan bahwa laki-laki yang pulang ke rumah asalnya setelah nyentana akan disebut duda mulih truna dimana kedudukan hukum di rumah asalnya kembali seperti bujang (pemuda yang belum pernah menikah) tetapi tidak berkedudukan sebagai ahli waris lagi di rumah asalnya. Menurut awig-awig di Banjar Pujung Kaja Desa Sebatu, hak mewaris duda mulih truna di rumah asalnya sudah dianggap hilang, dan seorang duda mulih truna sudah dianggap ninggal kedaton (meninggalkan semua hak dan kewajiban) di rumah asalnya.
\end{abstract}

Kata kunci: Duda mulih truna, Hak Mewaris, Perkawinan Nyentana

\begin{abstract}
Balinese people adhere to the patrilineal family system. In Bali, the position of a man (purusa) is very important. There are several types of marriages in Bali, one of which is a Nyentana marriage. A man who carries out a Nyentana marriage is where a man is married by a woman and the marriage ceremony is held at the women's home. In Nyentana marriage there are many things that affect the occurrence of divorce, one of which is the problem of inheritance. Men who have been married in Nyentana marriage, then return to their original homes, no longer have the right to inherit in their original home because all of their inheritance rights have been lost since they legally carried out Nyentana marriages. Based on the above background, this study was conducted with the aim of outlining how the legal status of a Mulih Truna widower (Widower from Nyentana marriage) in his original home and how the right to inherit a Mulih Truna widower according to awig-awig (customary rules) in Banjar Pujung Kaja Sebatu Village. The method used in this legal research was empirical legal research methods. The results of this study indicated a man who returns to his original home after cessation will be called Mulih Truna widower where the legal position in his home returns to being like a bujang (young man who has never been married) but does not reside as an heir again in his home. According to awig-awig in Banjar Pujung Kaja Sebatu Village, the right of inheriting a Mulih Truna widower in his original home has been considered lost, and a Mulih Truna widower has been deemed to have left a kedaton (leaving all rights and obligations) in his home.
\end{abstract}

Keywords: Mulih Truna Widower, Inheritance Right, Nyentana Marriage

\section{PENDAHULUAN}

Perkawinan bagi semua orang merupakan impian akan kebahagiaan dan kehidupan yang menyenangkan. Dalam budaya Indonesia khususnya di Bali perkawinan memiliki arti penting (disakralkan) untuk melanjutkan keturunan dan mendapatkan peranan sosial dalam masyarakat dan pada dasarnya setiap individu perlu hidup bersama sebagai mahluk soasial dalam bermasyarakat untuk mencapai tujuan tertentu (Sudantra, Sukerti, \& Dewi, 2015). 
Di Bali ada beberapa macam jenis perkawinan salah satunya adalah perkawinan nyentana. Masyarakat Bali yang menerapkan perkawina nyentana adalah suatu keluarga yang tidak memiliki keturunan anak laki-laki sebagai ahli waris di rumahnya (Adnyani, 2017; Hemamalini \& Suhardi, 2015; Udytama, 2015). Maka dari itu keluarga tersebut harus mengangkat sentana, yaitu dengan meminang seorang anak laki-laki dan upacara perkawinannya dilakukan di rumah istrinya. Dalam perkawinan nyentana maupun perkawinan lainnya sudah pasti banyak terjadi masalah yang mempengaruhi terjadinya perceraian terutama masalah hak waris dalam perkawinan nyentana (Kaler, 1982).

Dalam perkawinan nyentana laki-laki yang sudah nyentana sudah kehilangan hak mewarisnya di rumah asalnya. Jadi, jika terjadi perceraian, seorang laki-laki tersebut disebut sebagai duda mulih truna dimana duda mulih truna ini tidak berhak lagi mewaris di rumah asalnya karena sudah dianggap ninggal kedaton (meninggalkan semua hak dan kewajibannya) di rumah asalnya (Ketut Meta, 2013; Puspa, Aprilianti, \& Nargis, 2018; Windia dkk., 2008). Namun, agar utuhnya perkawinan dan tidak terjadi perceraian sebagai suatu keluarga, suami istri wajib untuk saling mencintai, saling menghormati serta memberikan bantuan lahir batin demi tegaknya suatu keluarga yang kekal dengan kebahagiaan sepanjang umur.

Berdasarkan latar belakang masalah di atas, penelitian ini dilakukan dengan tujuan menguraikan bagaimana status hukum duda mulih truna di rumah asalnya dan bagaimana hak mewaris duda mulih truna menurut awig-awig di Banjar Pujung Kaja Desa Sebatu.

\section{METODE PENELITIAN}

Penelitian ini didesain dengan menggunakan pendekatan atau metode penelitian hukum empiris, yaitu penelitian dengan cara menggunakan fakta-fakta empiris yang diambil dari prilaku manusia baik prilaku verbal yang terdapat di masyarakat serta wawancara maupun dengan cara pendekatan sosial hukum dan prilaku nyata yang dilakukan melalui pengamatan langsung. Lokasi penelitian ini bertempat di Banjar Pujung Kaja Desa Sebatu Kecamatan Tegallalang Kabupaten Gianyar. Lokasi ini dipilih karena di Banjar Pujung Kaja, perkawinan nyetana masih dilestarikan. Sumber data penelitian ini adalah kelihan banjar adat di Banjar Pujung Kaja. Data diperoleh dengan menggunakan metode wawancara dan observasi. Setelah data diperoleh selanjutnya diolah dan dianalisis dengan menggunakan argumentasi hukum berdasarkan logika hukum deduktif-induktif serta disajikan secara deskriptif.

\section{HASIL PENELITIAN DAN PEMBAHASAN}

Perkawinan bagi semua orang kata itu merupakan impian akan kebahagiaan dan kehidupan yang menyenangkan. Dalam budaya Indonesia khususnya di Bali perkawinan memiliki arti penting (disakralkan) untuk melanjutkan keturunan dan mendapatkan peranan sosial dalam masyarakat. Dan pada dasarnya setiap individu perlu hidup bersama sebagai mahluk soasial dalam bermasyarakat untuk mencapai tujuan tertentu.

Perkawinan nyentana adalah perkawinan dimana pihak perempuan yang meminang si pihak laki-laki dan upacar perkawinannya di laksanakan di rumah perempuan dan laki-laki yang sudah sah melalukan perkawinan nyentana hak mewaris dirumah asalnya dianggap sudah hilang karena laki-laki yang sudah nyentana sudah dianggap ninggal kedaton (meninggalkan semua hak dan kewajiban dirumah asalnya). Dalam perkawinan nyentana ada juga disebut duda mulih trun. Duda mulih truna adalah sebutan untuk laki-laki yang sudah pernah sebelumnya melakukan perkawinan nyentana dan kembali pulang ke asalnya akibat perceraian dan kembali berstatus kembali seperti bujang (Wijaya, 2014).

\section{Status Hukum Duda mulih truna di Rumah Asalnya}

Duda mulih truna muncul karena berasal dari dilaksanakan perkawinan nyentana dimana perkawinan nyentana adalah suatu istilah yang diberikan kepada sepasang calon suami istri dimana calon suami dipinang (diminta) oleh keluarga calon istri karena di Bali masih menganut sistem kekeluargaan patrilineal atau kapurusa. Dalam ilmu morfologi, nyeburin merupakan kruna tiron/ kata jadian, kata asalnya adalah cebur, mendapat anusara (tambahan kata) in maka menjadi nyeburin. Jadi nyuburin artinya melakukan tindakan nyebur, menyasar menuju sesuatu. Sedangkan nyeburin dalam sebuah istilah dapat diartikan sebagai nama sutu jenis/bentuk perkawinan menurut agama Hindu di Bali 
dalam mana sang wanita ditetapkan berkedudukan selaku purusa (laki-laki). Adapun pengertian perkawinan nyentana adalah perkawinan nyentana adalah perkawinan yang dilangsungkan antara seseorang laki-laki dengan seorang perempuan, dalam mana pihak laki-laki meninggalkan rumahnya, untuk melangsungkan upacara perkawinan di tempat kediaman istrinya, dan kemudian bertanggung jawab penuh meneruskan kewajiban (swadharma) orang tua serta leluhurnya istrinya, secara sekala (alam nyata) maupun niskala (alam gaib) (Tamanbali, 2017).

Dalam perkawinan nyentana, laki-laki akan berubah status hukum di keluarga istrinya. Lakilaki menjadi status pradana (perempuan) dan perempuan menjadi purusa (laki-laki). Laki-laki yang pulang kerumah asalnya setelah nyentana akan disebut duda mulih truna yang dimana kedudukan hukum di rumah asalnya kembali seperti bujang (pemuda yang belum pernah menikah) tetapi tidak berkedudukan sebagai ahli waris lagi di rumah asalnya dan pada saat ia kembali kerumah asalnya tidak ada alasan bagi keluarga untuk tidak menerima ia kembali pulang ke rumah asalnya karena pada konsep duda mulih truna, status hukum laki-laki yang kembali pulang setelah sah bercerai adalah pulang ke rumah keluarganya. Seorang anak (laki-laki/ perempuan) kembali pada rumah asalnya sudah kehilangan semua hak sebagai ahli waris pada rumah asalnya. Hubungan hukum kekeluargaannya dilepaskan dengan keluarga asalnya untuk selanjutnya masuk dalam pihak purusa (istri masuk kekeluarga suami untuk kasus perkawinan biasa atau suami masuk kekeluarga istri untuk kasus perkawinan nyeburin). Berakhirnya tanggung jawab hukum (hak dan kewajiban seseorang di keluarga asalnya terhitung sejak dilaksanakannya upacara mepejati atau bisa disebut juga dengan istilah mepamit di rumah asalnya (wawancara, kelihan banjar adat, 17 November 2019).

Duda mulih truna adalah seorang anak laki-laki yang sudah pernah melaksanakan perkawinan nyentana dan kembali pulang kerumah asalnya dan sesudah bercerai dan sudah ada keputusan pengadilan serta sudah ada pemberitahuan dari kelihan banjar yang menyatakan yang bersangkutan sudah sah bercerai. Dalam hal perkawinan nyentana seorang anak laki-laki yang melaksanakan perkawinan nyentana sudah dianggap ninggal kedaton (meninggalkan semua hak dan kewajiban dirumah asalnya). Maka dari itu kewajiban duda mulih truna di rumah asalnya dianggap sudah tidak ada lagi. Dalam kasus ini hal tersebut diperkuat dengan masih adanya saudara laki-laki dari sang duda mulih truna yang akan melaksanakan kewajiban terhadap orang tua di rumah asalnya (wawancara, kelihan banjar adat, 17 November 2019).

\section{Kedudukan Hak Mewaris Duda mulih truna di Rumah Asalnya}

Pada umumnya soal hak mewaris sesudah melakukan perkawinan nyentana tentu saja hilang karena menurut hukum adat bali, patut dan tidak patutnya seorang mewaris tergantung dari sejauh mana ia melakukan kewajiban terhadap orang tua, masyarakat dan leluhurnya (sanggah/merajan). Kewajiban terhadap orang tua yaitu merawat orang tua saat orang tua sudah tidak mampu lagi untuk mencari nafkah dan merawat orang tua dalam keadaan sakit. Karena ia telah melakukan perkawinan nyentana, maka tidak lah mungkin lagi ia akan melakukan kewajiban terhadap desa adat yaitu ngayah banjar di tempat dimana ia dilahirkan. Kewajiban terhadap leluhur yaitu berupa tanggung jawab terhadap sanggah/ merajan atau kewajiban yang berhubungan dengan pelaksanaan agama Hindu, seperti melaksanakan upacara dewa yadnya disanggah atau merajan tempat ia dilahirkan.

Dalam hal perkawinan nyentana ini berarti seorang anak laki-laki yang melakukan perkawinannya nyentana sudah dianggap ninggal kedaton (meninggalkan hak dan kewajiban) maka dari itu laki-laki nyentana dianggap sudah putus hubungannya dengan keluarga asalnya hal ini diperkuat oleh awig- awig tentang kewajiban seseorang yang melakukan perkawinan nyentana (wawancara, kelihan banjar adat, 17 November 2019).

Adapun hak dan kewajiban duda mulih truna yang ada di Banjar Pujung kaja Desa Sebatu, yaitu: seorang duda mulih truna di rumah asalnya tidak lagi mempunyai hak (hak mewaris) karena sudah dianggap ninggal kedaton, meninggalkan semua hak dan kewajibannya, akan tetapi orang tua kandungnya menerima ia dengan baik untuk kembali pulang. Ia hanya diberikan sebatas sepetak (a bungkul) kamar tidur utuk tempat tinggal saja. Warisan seperti tanah kebun, sawah dan lain-lain ia tidak berhak lagi untuk mendapatkan bagian karena di rumah asalnya tersebut ia masih mempunya saudara laki-laki yang berhak mewaris, terkecuali ada kebijakan dari keluarganya ia di berikan sedikit harta warisannya oleh saudara laki-lakinya tersebut untuk dinikmatinya kelak (diberikan secara cumacuma). Kewajiban duda mulih truna di Banjar Pujung Kaja, Desa Sebatu adalah seorang duda mulih truna hanya berkewajiban di ruang lingkup keluarga asalnya saja yaitu mulai dari merawat orang tua, 
menjaga kesucian tempat suci yang ada di lingkungan rumahnya, menggantikan orang tua dalam kegiatan petedunan banjar (gotong royong di banjar) jika orang tua berhalangan hadir. Selain kewajiban tersebut sudah tidak ada tanggung jawabnya karena ia sudah tidak mempunyai tanggung jawab kemasyarakatan lagi, seperti mekrama banjar yang harus selalu hadir di setiap kegiatan yang dilaksanakan oleh krama banjar setempat (wawancara kelihan banjar adat 17 November 2019).

\section{SIMPULAN DAN SARAN}

1. Simpulan

Berdasarkan hasil penelitian yang dipaparkan di atas, ada beberapa simpulan yang dapat dibuat, yaitu: pertama, status hukum duda mulih truna dalam perkawinan nyentana, laki-laki akan berubah status hukum di keluarga istrinya, laki-laki menjadi status pradana (perempuan) dan perempuan menjadi purusa (laki-laki). Laki-laki yang pulang kerumah asalnya setelah nyentana akan di sebut duda mulih truna dimana kedudukan hukum di rumah asalnya kembali seperti bujang (pemuda yang belum pernah menikah), tetapi tidak berkedudukan sebagai ahli waris lagi di rumah asalnya. Pada saat ia kembali kerumah asalnya tidak ada alasan bagi keluarga untuk tidak menerima ia kembali pulang kerumah karena pada konsep duda mulih truna status hukum laki-laki yang kembali pulang setelah sah bercerai, status hukumnya adalah kembali ke rumah asalnya, namun sudah kehilangan semua hak sebagai ahli waris pada rumah asalnya karena laki-laki yang sudah pernah melaksanakan perkawinan nyentana sudah dianggap ninggal kedaton (meninggalkan semua hak dan kewajiban) di rumah asalnya. Kedua, hak mewaris duda mulih truna di rumah asalnya sudah dianggap hilang karena seorang duda mulih truna sudah dianggap ninggal kedaton (meninggalkan semua hak dan kewajiban) dirumah asalnya. Hal ini mengacu pada pawos75 ayat (4) dan ayat (5) yang digunakan sebagai patokan. Sudah jelas pasal tersebut menjelaskan bahwa hak mewaris duda mulih truna tidak dapat diminta karena sudah dianggap ninggal kedaton (meninggalkan semua hak dan kewajiban).

\section{Saran}

Ada beberapa saran yang perlu disampaikan kepada beberapa pihak berdasarkan hasil penelitian ini, yaitu: pertama kepada keluarga diharapkan untuk melakukan pamerasan atau pengangkatan anak kembali terhadap anak yang melakukan perkawinan nyentana agar statusnya jelas dimasyarakat atau mengembalikan status purusa dalam keluarga asalnya akibat perceraian dan tidak meninggalkan hak dan kewajiban terhadap anak-anak yang lahir dari perkawinan tersebut dan sebaliknya dari anak kepada orang tuanya. Kedua, kepada prajuru adat agar lebih memperhatikan hak waris sentana mulih daha atau membuatkan aturan khusus mengenai perkawinan nyentana, dan mengadakan revisi terhadap awig-awig yang sudah ada agar seorang yang akan melakukan perkawinan nyentana tidak takut dengan resiko perceraian, dan apabila ia kembali kerumah asalnya tidak kehilangan hak warisnya, dan statusnya jelas setelah bercerai.

\section{DAFTAR PUSTAKA}

Adnyani, N. K. S. (2017). Sistem Perkawinan Nyentana dalam Kajian Hukum Adat dan Pengaruhnya terhadap Akomodasi Kebijakan Berbasis Gender. Jurnal Ilmu Sosial Dan Humaniora, 6(2), $168-177$.

Hemamalini, K., \& Suhardi, U. (2015). Dinamika Perkawinan Adat Bali: Status dan Kedudukan Anak Sentana Rajeg Menurut Hukum Adat dan Hukum Hindu. Dharmasmrti, XIII(26), 36-47.

Kaler, I. G. K. (1982). Butir-Butir Tercecer tentang Adat Bali. Denpasar: Bali Agung.

Ketut Meta. (2013). Pengangkatan Sentan Rajeg dalam Perspektif Hukum Perkawinan Adat Bali. Cakrawala Hukum, 18(1), 156-165.

Puspa, N. K. P. S., Aprilianti, \& Nargis, N. (2018). Pelaksanaan Perkawinan Nyentana pada Masyarakat Adat Bali (Studi pada Masyarakat Adat Bali di Desa Rama Nirwana Kecamatan Seputih Raman Lampung Tengah). Pactum Law Journal, 1(4), 375-387.

Sudantra, I. K., Sukerti, N. N., \& Dewi, A. A. I. A. A. (2015). Pengaturan Perkawinan pada Gelahang Dalam Awig-Awig Desa Pakraman. Jurnal Magister Hukum Udayana (Udayana Master Law Journal), 4(3), 575-587.

Tamanbali, I. K. S. (2017). Hak Waris Sentana Mulih Daha (Pulang Kembali) Akibat Perceraian Menurut Hukum Adat Bali (Universitas Airlangga).

Udytama, I. W. W. W. (2015). Status Laki-Laki dan Pewarisan dalam Perkawinan Nyentana. Jurnal 
Jurnal Interpretasi Hukum Vol. 1, No. 1 2020, Hal. 186-190

Advokasi, 5(1), 73-88.

Wijaya, K. P. A. (2014). Kedudukan Hukum Suami Isteri dalam Perkawinan Pada Gelahang Menurut Hukum Adat Bali (Universitas Jember).

Windia dkk., W. P. (2008). Perkawinan Pada Gelahang di Bali. Denpasar: Udayana University Press. 